\title{
Determining the Physical and Mechanical Properties of Two-Phase Soil for Landslide Slopes of the Northern Tien Shan
}

\author{
Aigerim Baimakhan', Assima Seinassinova², Rysbek Baimakhan², \\ Aiman Rysbayeva ${ }^{4}$ and Nazgul Moldakunova ${ }^{5}$ \\ ${ }^{1}$ Atyrau University, Kazakhstan. \\ ${ }^{2}$ Civil Aviation Academy, Kazakhstan. \\ ${ }^{3}$ Institute of Mechanics and Mechanical Engineering of the National Academy of Sciences, Kazakhstan. \\ ${ }^{4}$ Kazakh Leading Academy of Architecture and Civil Engineering, Kazakhstan. \\ ${ }^{5}$ Issyk-Kul State University named after K. Tynystanov, Kyrgyzstan.
}

\begin{abstract}
This article presents a comprehensive examination of the physical and mechanical properties of cover soils characteristic of the landslide slopes of Ak Kain, Kok Tobe, and Shym Bulak of the Trans-Ili Alatau, which are located in close proximity to the borders and in the city of Almaty itself. By analyzing previous known landslides in the region, and of a similar type in some countries, the authors identify three main reasons for the occurrence of a landslide on these mountain slopes. These include the water saturation of slope cover soils absorbed during spring rainfall, as well as technogenic and gravitational reasons. The authors conclude that landslides are often caused by soil water saturation. Therefore, it is proposed to consider slope soils as a two-phase medium. The algorithm for determining the physical and mechanical properties of two-phase soil is generalized, and specific calculations are performed based on the considered methods and algorithms. The results obtained for some types of loose soils, such as sandy loam, loam and clay varieties, are given in a systematic form in the tables, which are necessary for an extensive study of the mechanisms of occurrence of landslide processes in water-saturated soils of these slopes through stress-strain state determination.
\end{abstract}

Keywords: Mountain slope, soil, landslide, filtration, water saturation, two-phase medium.

\section{INTRODUCTION}

Landslide processes continuously occur on the slopes of the Northern Tien Shan, as in other mountainous regions of the world. It is known that there are diverse types of landslides depending on the type, nature, scale and speed of displacement, the volume of transported mass, etc. When the Ak Kain landslide occurred, which is located between Almaty and its satellite city, Talgar, about a million tons of landslide mass moved from the mountain slope in the spring of 2004. Overcoming about $500 \mathrm{~m}$ almost in an instant, it covered a two-story residential building and killed 28 residents. During the Kol Sai landslide in the spring of 2018, a landslide mass of about 50 million tons, $900 \mathrm{~m}$ wide and $177 \mathrm{~m}$ long, moved continuously for 5 days.

The condition of the Kok Tobe mountain slope has always been alarming and today causes concern for the residents of the eastern part of Almaty due to landslide danger, not to mention modern high-rise buildings and structures, constructed along Dostyk Avenue directly at the foot of the mountain, and the western slope being densely populated and built up.

The landslide condition of this mountain has not yet been investigated by modern methods of mathematical modeling, computational mathematics, computer graphics, geomechanics, and by drilling ultra-deep wells to the bedding rock. The height of Kok Tobe mountain is $250 \mathrm{~m}$, and the height of the TV tower built on its western slope on loose soils is $372 \mathrm{~m}$. Back in the early spring of 2005, after heavy rains on Kok Tobe, an emergency occurred - significant cracks appeared on the surface of the mountain, soil began to slide and buildings collapsed. There was a real threat of the landslide descending into the nearby residential areas.

The conditions of these landslide slopes also have not been investigated by modern geomechanics methods and special drilling from the point of view of stability and strength, with regard to the anisotropy of the structure and the degree of water saturation. In addition, their physical and mechanical properties, which transform into a two-phase state before the landslide, are unknown. The latter question is the main one at the initial stage of research.

\section{REVIEW OF LANDSLIDE SLOPE CONDITIONS OF THE NORTHERN TIEN SHAN}

One of the biggest problems in the construction of the TV tower was loose loamy soil, which makes up the slope of Kok Tobe.

The project for the construction of a TV tower on Kok Tobe was undertaken by two Moscow institutes, Melnikov and Fundamentproekt, as well as the Kazakhstan branch of 
Melnikov Central Research and Design Institute of Steel Structures. The TV tower, as shown in Figure 1, was built on the soft soils of the western slope of Kok Tobe.

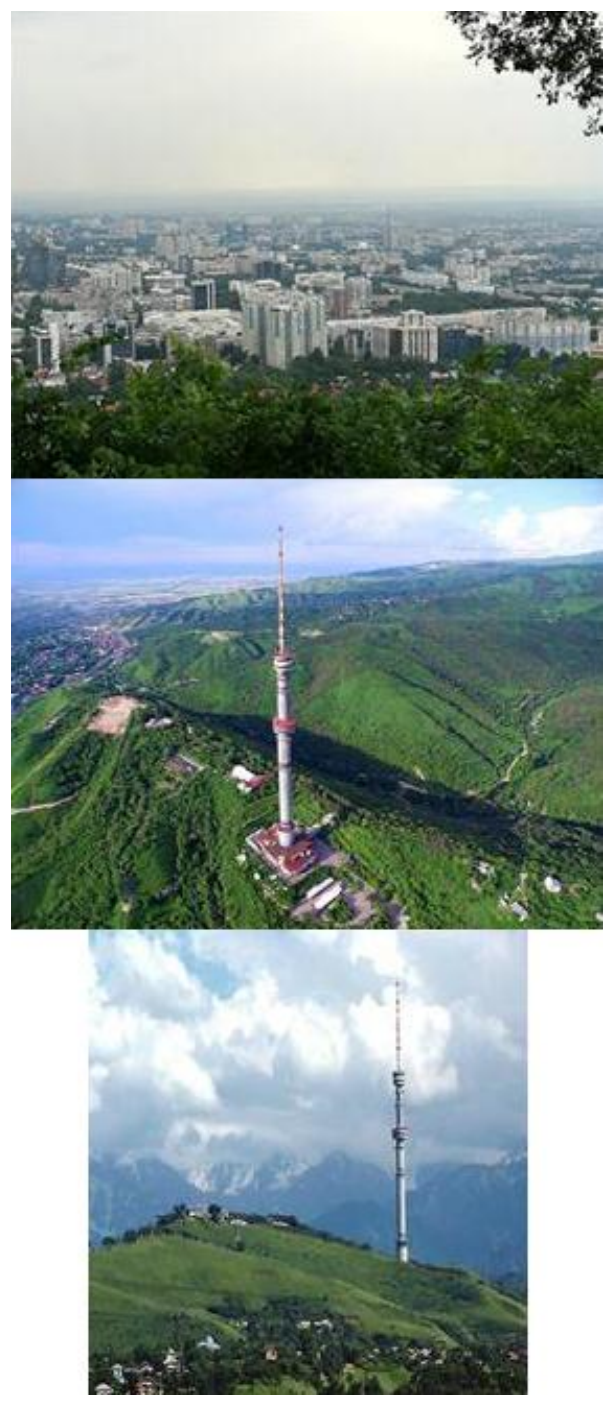

Fig. 1. The eastern and north-western slopes of Kok Tobe mountain (pictures on the left) and high-rise buildings of Almaty located at the foot of these slopes (picture on the right)

Kok Tobe mountain soils composed of loam varieties are unstable [1]. In subsequent years, cracks formed on Sakhariyev Street near the eastern bypass road (Figure 2). A general analysis of the occurrence of landslide processes that took place on the mountain slopes of the Northern Tien Shan makes it possible to conclude that, besides water saturation, they are caused by technogenic factors, that is, undercutting carried out for road construction. Another reason is the slow gravitational processes associated with tectonic compression of the sedimentary stratum of the earth's crust. This is evidenced by noticeable and measurable tectonic forces. As a result, the Trans-Ili Mountains rise at a speed of $1.5 \mathrm{~cm}$ per year. If, due to tectonic compression, the mountain ranges rise, then gravitational compression leads to the flattening of the soil of mountain slopes and various hills. This means that the slow shear and separation movements of saturated soil mass are shifted from weakly held areas towards lower stepped, close to horizontal, areas. This is how one can explain the occurrence of the Kol Sai landslide on quiet days without noticeable rainy weather. Its continuous movement lasted 5 days. This process is a prime example of the gravitational cause of a landslide. One of the important questions of studying the causes and mechanisms of landslide processes is the examination and definition of the structure and the physical and mechanical properties of cover soils. It is especially important to study anisotropic properties. The content of such research was systematized by A.K. Bugrov and A.I. Golubev [2]. Later, these issues were addressed by such Kazakhstani scientists as R.B. Baimakhan, N. Kurmanbekkyzy [3], A.K. Rysbayeva, A.A. Seinassinova, A.R. Baimakhan and others [4], [5].

The immediate cause of the Ak Kain landslide is associated with heavy rainfall that had been falling for several days in a row. The Kok Tobe landslides occurred both in dry weather and in rainy seasons. They were also caused by cutting lower slopes during the construction of the Eastern bypass road through the North-Western foot of Kok Tobe (Figure 2, picture on the left). Landslides tend to occur in this area, despite retained walls, as a result of the disturbance of the natural stress state.

Due to heavy rainfall, back in 2005 , the soils on the slope gradually began to slide. Having examined the eastern slope, municipal agencies found a crack $2.5 \mathrm{~m}$ high, $5 \mathrm{~m}$ wide and $1.5 \mathrm{~m}$ deep, which is shown in Figure 2. The landslide posed a threat to house No. 93a. Two more houses, No. 87 and 87a, were also at risk.

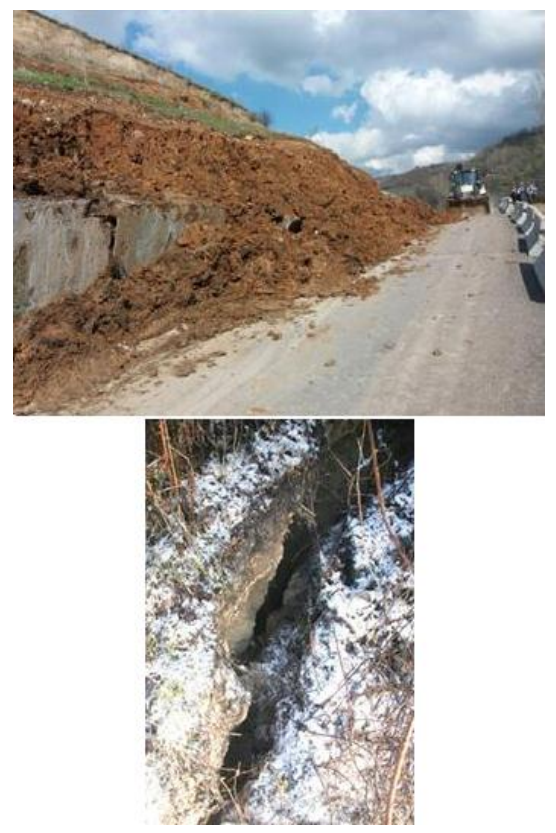

Fig 2. Kerege - a rope, folding lattice walls and a large piece of felt covering the structure

As emphasized by V. S. Shevchenko, "All the foothill areas of Almaty are continuous dangerous zones. The geological structures of local soils are weak. Therefore, the elite areas of Almaty, namely Kok Tobe, Kamenskoe Plateau, Butakovka, and Remizovka, are unsuitable for construction". 
According to Professor V.A. Khomyakova, "In the depths of the earth, the water drying process is much slower. According to scientists, soil moisture on the surface is $15-16$ percent. In theory, at a depth, the figure is supposed to decrease, but it reaches only 22-25 percent" [7]. This opinion is shared by V. Shevchenko: "It turns out, due to the penetration of melt, atmospheric and communication water, the soils adjacent to the soil and plant layer are more water-saturated. Before starting any construction on the slope and under it, one should calculate whether it will be strengthened or not. To do this, it is necessary to check its stability and moisture. All slopes over the years become heavier due to humidity." These statements indicate a two-phase state of cover soils, especially in spring during the heavy rainy season. The soils of landslide slopes in other countries are nearly in the same condition.

The consequences of soil water saturation were considered by Massimiliano Alvioli, Massimo Melillo, Fausto Guzzetti, Mauro Rossi, and Silvia Peruccacci [6]. When modeling the mechanisms of rainfall-induced shallow landslides, Qihua Ran, Yanyan Hong, Wei Li, and Jihui Gao paid attention to various rainfall characteristics [7]. Abid Ali, Jinsong Huang, A. V. Lyamin, S. W. Sloan, and J. H. Li [8] also indicated the influence of rainfall as one of the causes of landslides on mountain slopes. Laura Longoni, Monica Papini, Davide Brambilla, Diego Arosio, and Luigi Zanzi presented models for the Ronko landslide on a deep gravitational slope in Italy [9]. One of the landslide areas is mountain slope sections cut off for road construction. The work of Slavka Harabinova [10] is devoted to an assessment of slope stability on roads. The cover soils of the slopes are often formed by loesses. Yanqiu Leng, Jianbing Peng, Qiyao Wang, Zhenjiang Meng, Weiliang Huang investigated a loess landslide occurred in the South Jingyang tableland [11].

In 2017 alone, in the early spring, 64 cases of spontaneous landslides occurred in the eastern territory of Almaty. In May, due to abrupt warming, melting snow and heavy rains, 35 landslides were recorded.

A review and analysis of Kok Tobe data suggests that a dangerous accumulation of water in the deep layers is taking place in the soils of its slopes. When it reaches the surface of the underlying rock, there is a likelihood of a sudden slip of soil mass over them. An examination of the condition of these landslide-hazardous slopes should start with the calculation values of physical and mechanical properties for the twophase soil state.

\section{ALGORITHM FOR CALCULATING PHYSICAL AND MECHANICAL PROPERTIES OF TWO- PHASE SOIL}

The issues of determining the elastic properties of wet soil were addressed by B.M. Cherepanov [12], A.B. Alyushin, Z.G. Ter-Martirosyan [13], and those of water-saturated two-phase soil - by L.A. Eisler and others [14, 15]. The value of the elastic modulus $E^{V}$ can be calculated from the usual expressions of the theory of elasticity, using the experimental data of the modulus of shear $G_{0}$ or volume strain $K_{0}$. Z.G. TerMartirosyan presented some of these dependences for water- saturated soil [15]. Figures $3 a$ and $3 b$ show graphical dependences from this work. As can be seen, an increase in the moisture content $W$, at different skeleton densities, leads to a decrease in the modulus of shear $G_{0}$ and volume strain and strength characteristics $C$ and $\varphi$.
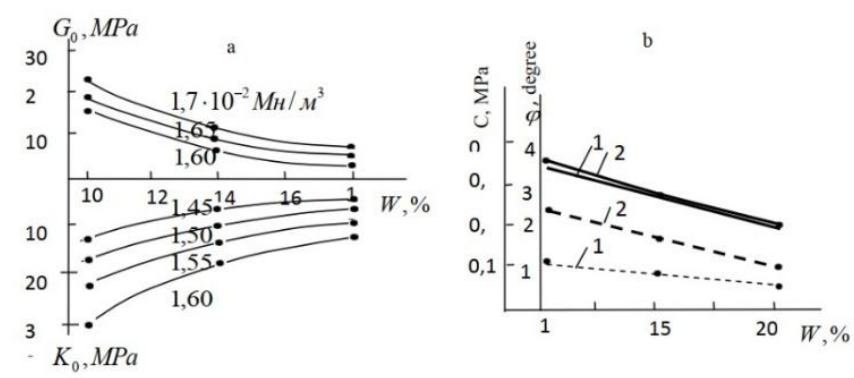

Fig 3. Graphs of dependences on unsaturated soil moisture: a - of the modulus of shear $G_{0}$ and volume strain $K_{0}$ at different skeleton densities, $\mathrm{b}$ - of the adhesion $C$, the internal friction angle $\varphi$

For theoretical model calculations, except for L.A. Eisler's work, there are no explicit analytical expressions to determine Young's modulus $E^{V}$, Poisson's ratio $v$, and the volume weight $\gamma, 1 \cdot 10^{2} \mathrm{MN} / \mathrm{m}^{3}$ for water-saturated soil $[15,16]$.

For each step of increasing moisture, by taking the values $G_{0}$ or $K_{0}$ from these graphs, Young's modulus $E^{V}$ for moisturesaturated soil can be calculated using one of the following formulas:

$$
E^{V}=2 G_{0}(1+v), \quad E^{V}=3 K_{0}(1-2 v)
$$

Since the value of Poisson's ratio $v$ changes insignificantly and almost does not affect the results of the elastic calculation, it can be left constant.

In the experimental determination of the elastic properties of a multicomponent material, errors are introduced due to averaging in the form of a quasi-homogeneous material. Such errors are also inevitable in theoretical consideration, which affect the result of studying the laws of stress distribution and concentration in the object. Below are some approximate considerations of this issue for water-saturated soil.

According to [15], [16] and [17], the modulus of soil volume compression $K_{V}$ is calculated by the expression

$$
K_{V}=\frac{E_{\Gamma}}{3\left(1-2 v_{\Gamma}\right)},
$$

where $E_{\Gamma}$ and $v_{\Gamma}$ are the elastic modulus and Poisson's ratio for dry soil, respectively. The effective bulk modulus for watersaturated soil is determined by the combinations of moduli for solid particles $K_{T}$ and water $K_{\mathrm{B}}$ :

$$
K_{T}=\frac{E_{T}}{3\left(1-2 v_{T}\right)}
$$




$$
\begin{aligned}
& K_{\mathrm{B}}=\frac{E_{\mathrm{B}}}{3\left(1-2 v_{\mathrm{B}}\right)}, \\
& K^{+}=\frac{K_{T} K_{\mathrm{B}}}{K_{T}-K_{\mathrm{B}}}
\end{aligned}
$$

Although in its pure form, water is incompressible, in practice there are experimentally established values. It is known that in artillery installations the property of the low volume compressibility (elasticity) of a liquid is used for hydraulic resistance. Thus, it was found that volume water compression has the following value: $K_{\mathrm{B}}=2000 \mathrm{MPa}$ [16]. Based on the above relations, following L.A. Eisler [14], we can write down an expression of elastic characteristics for an averaged material that simulates water-saturated soil. Now, for a quasione-component medium, taking into account their joint movement, for volume compression, we have

$$
K_{V}^{\ni}=\beta K^{*}
$$

where

$$
\begin{aligned}
& \beta=1+\frac{n K_{V}}{K^{+}}, \\
& K^{*}=\frac{K_{T} K_{\mathrm{B}}}{n K_{T}+m K_{\mathrm{B}}}
\end{aligned}
$$

is the volume compression modulus of saturated soil mass, $n$ and $m$ are the volume proportion content of solid and liquid (gas-saturated) soil components.

Similarly, the elastic modulus of water-saturated soil $E^{\ni}$, Poisson's ratio $v^{\ni}$ and the shear modulus $G^{\ni}$ are calculated by the expressions:

$$
\begin{aligned}
& E^{\ni}=\frac{9 \beta K^{*} G}{3 \beta K^{*}+G} \\
& v^{\ni}=\frac{3 \beta K^{*}-2 G}{2\left(3 \beta K^{*}+G\right)}, \\
& G^{\ni}=G .
\end{aligned}
$$

Let us specify the degree of soil porosity according to N.A. Tsytovich's formula [16]:

$$
\eta=\frac{n}{m} \text { or } \eta=\frac{n}{1-n} \text {. }
$$

As seen, $n+m=1$. They directly enter the expression for $K^{*}$. According to (8), soil types can be established. In this regard, $\eta$ values equal to $0.2 \div 1.5$ correspond to ordinary soil, $2 \div 12$ - to organo-mineral soil, or $\eta<1$ defines

\begin{tabular}{|c|c|c|c|c|c|c|}
\hline Soil type & $\begin{array}{c}E_{\Gamma}, \\
\mathrm{MPa}\end{array}$ & $\begin{array}{l}v_{\Gamma}, \\
\mathrm{MPa}\end{array}$ & $\begin{array}{l}n, \\
\%\end{array}$ & $\begin{array}{l}m, \\
\%\end{array}$ & $\begin{array}{c}E^{\ni}, \\
\mathrm{MPa}\end{array}$ & $\begin{array}{c}v^{\ni}, \\
\text { МПа }\end{array}$ \\
\hline \multirow{4}{*}{$\begin{array}{l}\text { Varved } \\
\text { layered } \\
\text { soft } \\
\text { plastic } \\
\text { clay }\end{array}$} & \multirow{4}{*}{8} & \multirow{4}{*}{0,42} & 90 & 10 & 7,99 & 0,419 \\
\hline & & & 80 & 20 & 7,97 & 0,418 \\
\hline & & & 70 & 30 & 7,92 & 0,406 \\
\hline & & & 60 & 40 & 7,81 & 0,390 \\
\hline \multirow{4}{*}{$\begin{array}{l}\text { Firm } \\
\text { sandy } \\
\text { loam }\end{array}$} & \multirow{4}{*}{9} & \multirow{4}{*}{0.32} & 90 & 10 & 8.99 & 0.318 \\
\hline & & & 80 & 20 & 8.93 & 0.310 \\
\hline & & & 70 & 30 & 8.81 & 0.292 \\
\hline & & & 60 & 40 & 8.54 & 0.253 \\
\hline \multirow{4}{*}{ Loam } & \multirow{4}{*}{12} & \multirow{4}{*}{0,40} & 90 & 10 & 11,99 & 0,399 \\
\hline & & & 80 & 20 & 11,95 & 0,394 \\
\hline & & & 70 & 30 & 11,85 & 0,383 \\
\hline & & & 60 & 40 & 11,65 & 0,360 \\
\hline \multirow{4}{*}{$\begin{array}{l}\text { Fluid } \\
\text { sandy } \\
\text { loam }\end{array}$} & \multirow{4}{*}{18} & \multirow{4}{*}{0,31} & 90 & 10 & 17,97 & 0,308 \\
\hline & & & 80 & 20 & 17,86 & 0,300 \\
\hline & & & 70 & 30 & 17,59 & 0,280 \\
\hline & & & 60 & 40 & 17,04 & 0,257 \\
\hline \multirow{4}{*}{$\begin{array}{l}\text { Thin- } \\
\text { layered } \\
\text { firm clay }\end{array}$} & \multirow{4}{*}{300} & \multirow{4}{*}{0,35} & 90 & 10 & 299,63 & 0,348 \\
\hline & & & 80 & 20 & 298,40 & 0,342 \\
\hline & & & 70 & 30 & 294,59 & 0,326 \\
\hline & & & 60 & 40 & 287,23 & 0,293 \\
\hline
\end{tabular}
compacted soil, $\eta>1-$ loose soil.

\section{CALCULATIONS AND RESULTS}

Based on formulas (1) - (8), we calculated the elastic properties of water-saturated soils composing landslide slopes with various variations in the ratio of solid and liquid soil components. The results are given in Table 1 .

Tab. 1. Elastic properties of the major soils of landslide slopes depending on the degree of water saturation

Note: $E_{\Gamma}-$ the elastic modulus at natural soil moisture; $v_{\Gamma}$ - Poisson's ratio at natural soil moisture; $n-$ the proportion of solid component in the soil; $m$ - the proportion of liquid component in the soil; $E^{\ni}$ - the effective elastic modulus for water-saturated soil; $v^{\ni}$ - the effective Poisson's ratio for water-saturated soil

When the landslide mass shifts along the slope and there is an obstacle (bumps, roughness, etc.), the phenomenon of buckling will occur. Buckling in the broad sense is also possible during the natural process of water-saturated soil draining and on a global scale during tectonic compression. In all these cases, buckling occurs due to reverse compression or tensile strength. Therefore, it is appropriate to determine, at least theoretically, the value $\sigma_{\text {tens }}$ according to Mohr circles. 
If the critical strength parameters, the adhesion force $C$ and the internal friction angle $\varphi$, are known, then by applying them to the axis of the coordinate system $\tau \mathrm{O} \sigma$, one can easily determine the corresponding $\sigma_{\max }$ and $\sigma_{\min }$. According to D.H. Trollope, the latter with the opposite sign will correspond to tensile stress, i.e. $\sigma_{\text {tens }}=-\sigma_{\min }[18]$.

A complete set of physical and mechanical properties is compiled for soils indicated in Table 2, which contains values by N.S. Bulychev [18] and G. Kurmanbekkyzy [3]. Data in Table 3 were calculated according to N.N. Maslov [19]. The tensile shear strength $\sigma_{\text {tens }}$, the compressive shear strength $\sigma_{\text {compr }}$ and the ultimate shear strength $\tau_{\text {shear }}$ were theoretically determined through Mohr circles:

1) $\gamma_{c}=\frac{\gamma_{\Gamma}}{1+W}-$ the volume weight of the soil skeleton;
2) $\gamma_{y}=\frac{\gamma_{\Gamma}}{1-W\left(\gamma_{\Gamma}-1\right)}-$ the soil bulk density;

3) $n=\frac{\gamma_{y}-\gamma_{c}}{\gamma_{c}}-$ the soil porosity;

4) $\varepsilon=\frac{n}{1-n}-$ the porosity ratio;

5) the moisture capacity (soil moisture at a given porosity in case of the full water saturation): $W_{e}=\frac{E \gamma_{\Gamma}}{\gamma_{y}} * 100 \%$

6) the soil volume weight corresponding to the full moisture capacity: $\gamma_{e}=\gamma_{c}\left(1+\frac{W_{e}}{100}\right)$.

Table 2. Physical and mechanical properties of some water-saturated soils

\begin{tabular}{|c|c|c|c|c|c|c|c|}
\hline № & Soil type & $\begin{array}{l}W \\
\%\end{array}$ & $\begin{array}{c}\gamma_{\Gamma} * 10^{2} \\
\mathrm{MN} / \mathrm{m}^{3}\end{array}$ & $\begin{array}{r}\mathrm{C}^{*} 10^{2}, \\
\mathrm{MPa}\end{array}$ & $\varphi^{0}$ & $\begin{array}{c}v_{\Gamma}, \\
\mathrm{MPa}\end{array}$ & $\begin{array}{c}E_{\Gamma} \\
\mathrm{MPa}\end{array}$ \\
\hline 1 & Varved clay & 36 & 1.89 & 0.8 & 16 & 0.42 & 8 \\
\hline 2 & Firm sandy loam & 22 & 1.98 & 1.2 & 20 & 0.32 & 9 \\
\hline 3 & Loam & 20 & 2.04 & 2.0 & 22 & 0.40 & 12 \\
\hline 4 & Fluid sandy loam & 15 & 2.28 & 2.0 & 26 & 0.31 & 18 \\
\hline 5 & Thin-layered firm clay & 12 & 2.15 & 20.0 & 25.0 & 0.35 & 300.0 \\
\hline
\end{tabular}

Note: $W$ - the natural soil moisture; $\gamma_{\Gamma}$ - the soil volume weight; $\mathrm{C}-$ the adhesion coefficient; $\varphi$ - the internal friction angle; $v_{\Gamma}$ - Poisson's ratio; $E_{\Gamma}-$ the elastic modulus

Table 3. Critical stress values for different moisture

\begin{tabular}{|c|c|c|c|c|c|c|c|c|c|}
\hline № & $\begin{array}{c}\mathrm{n}, \\
\%\end{array}$ & $\varepsilon$ & $\begin{array}{c}W_{e}, \\
\%\end{array}$ & $\begin{array}{c}\gamma_{c}^{*} 10^{2}, \\
\mathrm{MN} / \mathrm{m}^{3}\end{array}$ & $\begin{array}{c}\gamma_{y} * 10^{2}, \\
\mathrm{MN} / \mathrm{m}^{3}\end{array}$ & $\begin{array}{c}\gamma_{e}^{*} 10^{2}, \\
\mathrm{MN} / \mathrm{m}^{3}\end{array}$ & $\begin{array}{c}\sigma_{\text {tens }} * 10^{2}, \\
\mathrm{MPa}\end{array}$ & $\begin{array}{c}\sigma_{\text {compr }}{ }^{*} 10^{2}, \\
\mathrm{MPa}\end{array}$ & $\begin{array}{c}\tau_{\text {shear }}{ }^{*} 10^{2}, \\
\mathrm{MPa}\end{array}$ \\
\hline 1 & 50.7 & 1.030 & 70 & 1.37 & 2.78 & 2.32 & 1.15 & 2.4 & 1,4 \\
\hline 2 & 35.8 & 0.558 & 44 & 1.62 & 2.52 & 2.33 & 1.78 & 3.09 & 2,25 \\
\hline 3 & 34.1 & 0.517 & 41 & 1.70 & 2.58 & 2.59 & 2.8 & 5,3 & 3,6 \\
\hline 4 & 29.2 & 0.425 & 34 & 1.98 & 2.82 & 2.65 & 2.7 & 6,2 & 3,8 \\
\hline 5 & 22.9 & 0.297 & 25 & 1.92 & 2.49 & 2.40 & 22,4 & 64,8 & 33,6 \\
\hline
\end{tabular}

Note: $n$ - the soil porosity; $\varepsilon$ - the porosity ratio; $W_{e},-$ the full moisture capacity; $\gamma_{C}-$ the volume weight of the soil skeleton; $\gamma_{y}$ - the soil bulk density; $\gamma_{e}-$ the soil volume weight at the full moisture capacity; $\sigma_{\text {tens }}-$ the tensile shear strength; $\sigma_{\text {compr }}-$ the compressive shear strength 
Table 4 shows the calculated water volumes that are required to reach the soil of a given moisture content at a unit volume. The moisture content was set in the range from natural moisture to the full moisture capacity. The calculations were also carried out according to Maslov's formulas [19] and $\mathrm{N}$. Kurmanbekkyzy's method [4]:

1) the soil volume weight corresponding to a given moisture content $\left(W_{3}\right): \gamma_{\text {g.moist. }}=\gamma_{c}\left(1+\frac{W_{3}}{100}\right)$;

2) the water volume weight: $q_{6}=\gamma_{c}\left(W_{3}-W\right)$.

Table 4. The water volume required to reach the soil of a given moisture content at a unit volume

\begin{tabular}{|c|c|c|c|}
\hline Soil type & $\begin{array}{c}W_{3}, \\
\%\end{array}$ & $\begin{array}{c}\gamma_{\text {g.moist }} * 10^{2}, \\
\mathrm{MN} / \mathrm{m}^{3}\end{array}$ & $\begin{array}{l}q_{6}, \\
\text { ton }\end{array}$ \\
\hline \multirow{3}{*}{$\begin{array}{l}\text { Varved } \\
\text { layered soft } \\
\text { plastic clay }\end{array}$} & 40 & 1,91 & 0,055 \\
\hline & 45 & 1,99 & 0,123 \\
\hline & 50 & 2,06 & 0,191 \\
\hline \multirow{3}{*}{$\begin{array}{c}\text { Firm sandy } \\
\text { loam }\end{array}$} & 30 & 2,11 & 0,129 \\
\hline & 35 & 2,19 & 0,210 \\
\hline & 40 & 2,27 & 0,291 \\
\hline \multirow{3}{*}{ Loam } & 25 & 2,13 & 0,085 \\
\hline & 30 & 2,21 & 0,170 \\
\hline & 35 & 2,29 & 0,255 \\
\hline \multirow{3}{*}{$\begin{array}{l}\text { Fluid sandy } \\
\text { loam }\end{array}$} & 20 & 2,38 & 0,099 \\
\hline & 25 & 2,48 & 0,198 \\
\hline & 30 & 2,57 & 0,297 \\
\hline \multirow{3}{*}{$\begin{array}{l}\text { Thin- } \\
\text { layered firm } \\
\text { clay }\end{array}$} & 15 & 2,21 & 0,057 \\
\hline & 20 & 2,30 & 0,153 \\
\hline & 25 & 2,40 & 0,249 \\
\hline
\end{tabular}

\section{CONCLUSIONS}

The water saturation of cover soils, such as loam, sandy loam, clay, and loess, can occur as a result of rainfall saturation (infiltration), rising subsoil water level (filtration), as well as anthropogenic impacts $[20,21]$. Studies related to determining the stability of landslide-hazardous slopes often use the physical and mechanical properties of soils in the mainly dry state due to the lack of data on the elastic properties of watersaturated soil. The data from the compiled tables can restore this gap, allowing us to fully explore the stress-strain state with regard to the two-phase state of slope soils.

\section{ACKNOWLEDGMENT}

This work is supported by a grant from the Science Committee of the Ministry of Education and Science of the Republic of Kazakhstan: Individual registration number AR05136194.

\section{REFERENCES}

[1]. Residents of 60 houses in Almaty were at risk due to the risk of landslide loss. Retrieved from: https://www.kt.kz/rus/society/zhiteli_60_domov_v_alm aty_okazalis_v_zone_riska_iz-za_1377890090.html

[2]. Bugrov AK, Golubev AI. Anisotropic soils and foundations of constructions. St. Petersburg: Nedra. 1993.

[3]. Kurmanbekkyzy N. Stability of mountain slope systems in the context of landslide and seismic hazard. The author's abstract of doctoral dissertation. Bishkek, 2010

[4]. Baimakhan AR, Rysbayeva AK, Seinassinova AA, Rysbayeva GP, Kulmaganbetova ZhK, Aliyeva AM, Baimakhan RB. Calculation of the Stress State of Certain Elements of Engineering Structures. International Journal of Applied Engineering Research, 11(12), 7698-7701, 2016.

[5]. Baimakhan AR. Development of a mathematical model and a set of programs for managing the state of the system "anisotropic soil-foundation-building". Almaty, 2017.

[6]. Alvioli M, Melillo M, Guzzetti F, Rossi M, Peruccacci S. Implications of climate change on landslide hazard in Central Italy. Science of the Total Environment, 630, 1528-1543, 2018.

[7]. Ran Q, Hong Y, Li W, Gao J. A modelling study of rainfall-induced shallow landslide mechanisms under different rainfall characteristics. Journal of Hydrology, 563, 790-801, 2018.

[8]. Ali A, Huang J, Lyamin AV, Sloan SW, Li JH. Simplified quantitative risk assessment of rainfallinduced landslides modelled by infinite slopes. Engineering Geology, 179, 102-116, 2014.

[9]. Longoni L, Papini M, Brambilla D, Arosio D, Zanzi L. The role of the spatial scale and data accuracy on deepseated gravitational slope deformation modeling: The Roncolandslide, Italy. Geomorphology, 253, 74-82, 2016.

[10]. Harabinová S. Assessment of Slope Stability on the Road. Procedia Engineering, 190, 390-397, 2017.

[11]. Leng Y, Peng J, Wang Q, Meng Z, Huang W. A fluidized landslide occurred in the Loess Plateau: A study on loess landslide in South Jingyang tableland. Engineering Geology, 236, 2018, 129-136, 2017.

[12]. Cherepanov BM, Alyushin AB. Investigation of the stress-strain state of a soaked loess base under a rigid 
International Journal of Engineering Research and Technology. ISSN 0974-3154 Vol.13, No.4 (2020), pp. 699-705

(C) International Research Publication House. https://dx.doi.org/10.37624/IJERT/13.4.2020.699-705

foundation stamp. I.I.Polzunov Altai State Technical University, 2000.

[13]. Martirosyan ZG. Forecast of mechanical processes in multiphase soil bodies. Moscow: Nedra, 1986.

[14]. Eisler LA. On the relationship between deformations of water-saturated soil components. News of All-Russia Research Institute of Hydraulic Engineering, 83, 359376, 1967.

[15]. Eisler LA. To the calculation of effective stresses in water-saturated soil under dynamic impacts. News of All-Russia Research Institute of Hydraulic Engineering, 80, 104-115, 1973.

[16]. Krasnikov ND. Seismic resistance of hydraulic constructions from soil materials. Moscow: Energoizdat, 1981.

[17]. Tsytovich NA. Soil mechanics. Moscow, 1979.

[18]. Bulychev NS. Mechanics of underground constructions in examples and tasks. Moscow: Nedra, 1989.

[19]. Maslov NN, Kotov MF, Zinyukhina NV. Problem book on soil mechanics. Moscow, 1963.

[20]. Khomyakov VA, Shokbarov YM, Bryantsev AA. Experience in Handling Differential Settlements of Multi-Storey Buildings on Soft Soil. Soil Mechanics and Foundation Engineering, 54(5), 330-335, 2017. https://doi.org/10.1007/s11204-017-9477-x

[21]. Khomyakov VA, Iskakov EE, Serdaliev ET. Investigation of gravelly soil during underground construction in Almaty. Soil Mechanics and Foundation Engineering, 50, 171-177, 2013. https://doi.org/10.1007/s11204-013-9230-z 